\title{
Stable Operation of Rotary Stoker Furnace for Industrial Waste
}

\author{
Koichi ShINOHARA ${ }^{1,2 *}$, Daisuke KONO ${ }^{1}$, Masayoshi MinAKAMI ${ }^{1}$, Tatsuya KAWAJIRI ${ }^{1}$, Shuji HiRONAKA ${ }^{2}$, and Jun FuKAI ${ }^{2}$ \\ ${ }^{1}$ Tsuneishi Kamtechs Corporation, 107-5 Minooki-cho, Fukuyama-shi, Hiroshima-ken, 721-0956 \\ ${ }^{2}$ Department of Chemical Engineering, Graduate School of Engineering, Kyushu University, 744 Motooka Nishi-ku, Fukuoka 819- \\ 0395, Japan
}

\begin{abstract}
Incineration is one of the most common methods for the treatment of industrial waste. Large amounts of bottom ash are buried without being reused. By reducing components such as toxic metals contained in bottom ash under suitable incineration conditions, landfill waste can be reduced, and re-use of bottom ash can be increased. In this study, effects of the air supplied to the bottom of a commercialy used rotary stoker furnace was investigated as the first step to improve incineration conditions. Bottom ash content must be controlled against various types of industrial waste whose content changes from day to day. The characteristics of industrial waste containing typical components were numerically investigated using a combustion simulation program. It was found that if the primary air used for combustion is not preheated, auxiliary fuel is required to burn waste. Preheated primary air increases the drying rate of the input material, and allows burning of waste without auxiliary fuel. At the furnace, components and calorific values of input raw material are controlled by mixing different types of waste together. Preheated primary air enables reduction of bottom ash, reduction of auxiliary fuel consumption, and stabilization of furnace operation.
\end{abstract}

\section{Introduction}

In Tsuneishi Kamtechs Corporation, bottom ash and fly ash generated from industrial waste incineration furnaces are recycled in various ways, e.g., slag production by melting and manufacture of artificial sand by a calcination process.

However, some of the generated ash cannot be recycled, and is disposed of in landfills.

Nationally, the remaining capacity of disposal sites is decreasing, and it requires a great deal of effort and time to set up new final disposal sites (Ministry of the Environment, 2018). Given this situation, there is an urgent need to develop a treatment process that can be used effectively without final disposal of ash. Existing techniques for effectively utilizing ash, in addition to production of slag by melting and production of artificial sand by calcination as described above, include use as cement raw material and use as aggregate. However, in order to use ash as cement raw material or aggregate, it is necessary to remove or reduce components such as salt, lead, zinc, and chromium in order to satisfy concentration standards for toxic metals that are specified by the receiving side.

Although Tsuneishi Kamtechs Corporation has repeated water washing experiments for demineralization of ash, the components that can be washed out with water are limited, and there are components that cannot be removed by washing, notably heavy metals. To remove these components, it is required to take measures from the waste incineration stage.

In the operation of present incineration facilities, auxiliary combustion materials are required which were not considered in the design. During operation, there are large variations in temperature within the furnace, and it is difficult to control the operating temperature, resulting in the inability of controlling the quality of the ash.

In this study, as a first step towards recycling of ash, a method to realize stable combustion in industrial waste incineration furnace was examined.

\section{Facility Used}

The industrial waste incineration facility of Tsuneishi Kamtechs Corporation, the subject of the present study, was built in 2002, and has been in commercial operation for 17 years. Figure 1 shows the processing flow of the incineration facility used in this study. The main combustion device of the facility is a water-cooled rotary stoker furnace (RC furnace). Here, waste incineration depends on the heat quantity of the input waste, the heat quantity of the auxiliary materials used (heavy oil A, heavy oil $\mathrm{C}$ ), and the heat quantity carried by the primary air.

\footnotetext{
* Corresponding author: koichi.shinohara@tsuneishi.com
} 


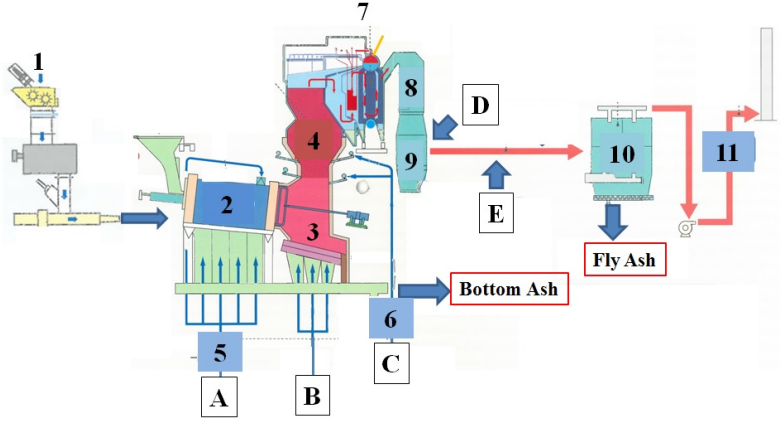

1. Drum Shredding-Mixing-Pumping system,

2. Rotary stoker, 3. Post combustion device,

4. Secondary combustion chamber, 5. Primary air preheater, 6. Secondary air preheater, 7. Waste heat boiler, 8. Economizer, 9. Cooling tower, 10. Bug filter, 11. Waste gas treatment

A. Primary air, B. Secondary air, C. Post combustion air, D. Caustic soda, E. Slaked lime

Figure 1. Incineration facility process flow

The waste in this incineration facility is supplied by 2 lines: a line called a mixing pit where various wastes are mixed, pooled and then supplied; and a line called a drum shredder convey or where waste, mainly solvents, is crushed while still in drums and then supplied to the furnace. Approx. $80 \%$ of waste is supplied from the pit, and approx. 20\% from the drum shredder conveyor.

The residue, after being burned in the RC furnace, is discharged as ash residue via a post combustion device. On the other hand, combustion gas and containing soot are recovered its heat by a boiler and economizer via a secondary combustion chamber, neutralized by caustic soda and slaked lime, collected by a bag filter, and discharged as fly ash (Inoue, 2008).

To maintain the legal temperature in the secondary combustion chamber, heavy oil A and water are used. There have been few studies on industrial waste treatment using the present type of incineration facility (Taniguchi et al., 1999).

\section{Experimental}

\subsection{Understanding of the present situation}

To analyze the states of combustion, a combustion simulation was performed.

The combustion process was analyzed using design tools developed by the manufacturer of the incineration facility. Coupled analysis of the two programs were performed: an original program simulating incineration of solids for waste layers, and "FLUENT" which is a universal thermal fluid analysis code for gas space (Narisawa, 2019; Denta et al., 2013; Yamaguchi et al., 2004). Table 1 shows the waste composition assumed in the design of the incineration facility, and the present waste composition.
Table 1. Comparison of design waste composition (Case-1), and present waste composition (Case-2)

\begin{tabular}{|c|c|c|c|c|}
\hline \multicolumn{2}{|c|}{ Item } & unit & $\begin{array}{c}\text { Case } \\
-1\end{array}$ & $\begin{array}{c}\text { Case } \\
-2\end{array}$ \\
\hline \multirow{9}{*}{$\begin{array}{c}\text { Waste } \\
\text { compo } \\
\text { sition }\end{array}$} & moisture & $w t \%(A R)$ & 26.22 & 42.22 \\
\hline & ash & $w t \%(A R)$ & 20.48 & 18.41 \\
\hline & $\begin{array}{c}\text { combusible } \\
\text { matter }\end{array}$ & wt\%(AR) & 53.3 & 39.37 \\
\hline & carbon & $w t \%(A R)$ & 33.21 & 27.01 \\
\hline & hydrogen & $w t \%(A R)$ & 4.21 & 3.37 \\
\hline & oxigen & wt\%(daf) & 13.01 & 7.36 \\
\hline & nitrogen & wt\%(daf) & 1.4 & 0.69 \\
\hline & sulfur & wt\%(daf) & 0.28 & 0.94 \\
\hline & chlorine & wt\%(daf) & 1.19 & 0.00 \\
\hline \multirow{2}{*}{\multicolumn{2}{|c|}{ Low heating value }} & $\begin{array}{c}\mathrm{MJ} / \mathrm{kg}- \\
\text { wet }\end{array}$ & 3200 & 2600 \\
\hline & & $\begin{array}{c}\mathrm{kcal} / \mathrm{kg}- \\
\text { wet }\end{array}$ & 13.5 & 11.0 \\
\hline
\end{tabular}

*The design process capacity is $160 \mathrm{t}$-wet/d $(6,667 \mathrm{~kg}$-wet $/ \mathrm{h})$

Compared to the waste composition used in the design, the present composition has more water, less flammables, and lower calorific value. Combustion simulations were performed using the waste composition of Case-2. Their results are shown in Figure 2.

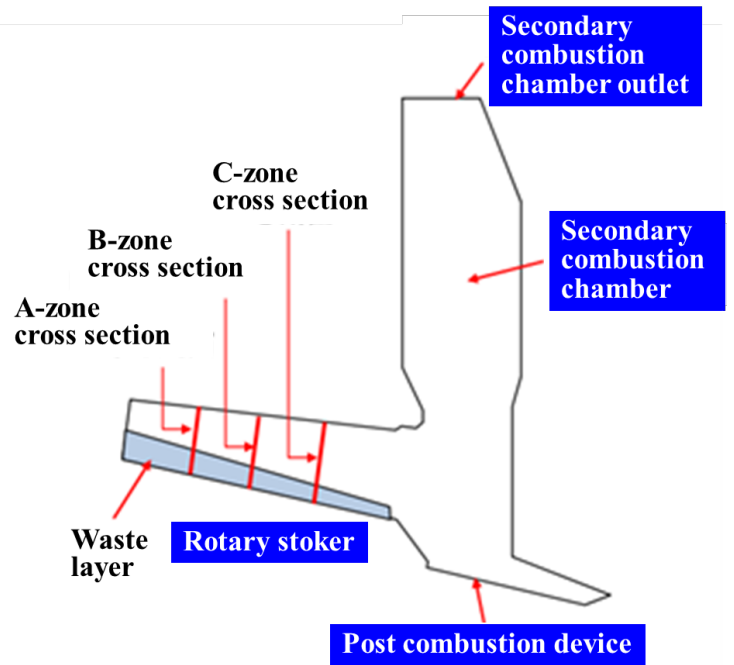

Figure 2. Configuration used for the analysis

\subsection{Effects of air preheater}

\subsubsection{Combustion simulation using preheated air}

For Case-2, it is considered that the high water content of the waste causes combustion in the RC furnace and postcombustion device to become unstable. Effective drying of methods of the waste were investigated by the combustion simulation. As one of the most effective methods, a combustion simulation was performed where 
the primary air and secondary air (hereinafter referred to collectively as "combustion air"), were preheated to $180^{\circ} \mathrm{C}$.

\subsubsection{Installation of air preheater}

A combustion air preheater (Hino-Tec Co., bare-tube heat exchanger type) was actually installed to the Incineration facility, and various data were collected when the combustion air was preheated. They were compared with the case where the combustion air was not preheated.

\section{Experimental results}

\subsection{Understanding of the present situation}

Figure 3 shows the result of combustion simulation in Case-2. The temperature is approx. $300^{\circ} \mathrm{C}$ throughout the incineration furnace, which indicates that combustion of waste has not progressed.

In actual operation, the temperature of the incineration furnace is maintained using auxiliary fuel. Thus, the temperature is controlled so that ambient temperature at the $\mathrm{RC}$ furnace outlet is $920-950^{\circ} \mathrm{C}$, while ambient temperature in the secondary combustion chamber is 800

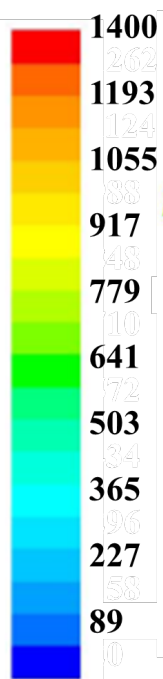

$\left({ }^{\circ} \mathrm{C}\right)$

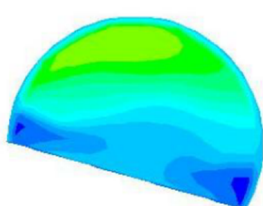

A-zone cross section

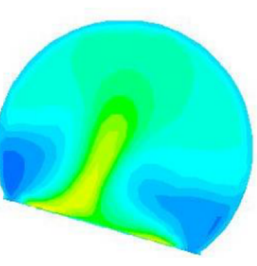

C-zone cross section $850^{\circ} \mathrm{C}$.

Figure 3. Results of combustion simulation with present waste composition (Case-2)

\subsection{Effects of air preheater}

\subsubsection{Combustion simulation with the waste composition of Case-2 when combustion air is preheated to $180^{\circ} \mathrm{C}$}

Figure 4 shows the results. The high temperature region of $900^{\circ} \mathrm{C}$ enlarges from B-zone onwards, and it can be seen that combustion proceeds through the whole incineration furnace.

\subsubsection{Installation of air preheater}

Figure 5 shows the relation between heat quantity of waste (wet basis)(kcal/kg-wet), and amount of auxiliary fuel. The square shows the case when combustion air is
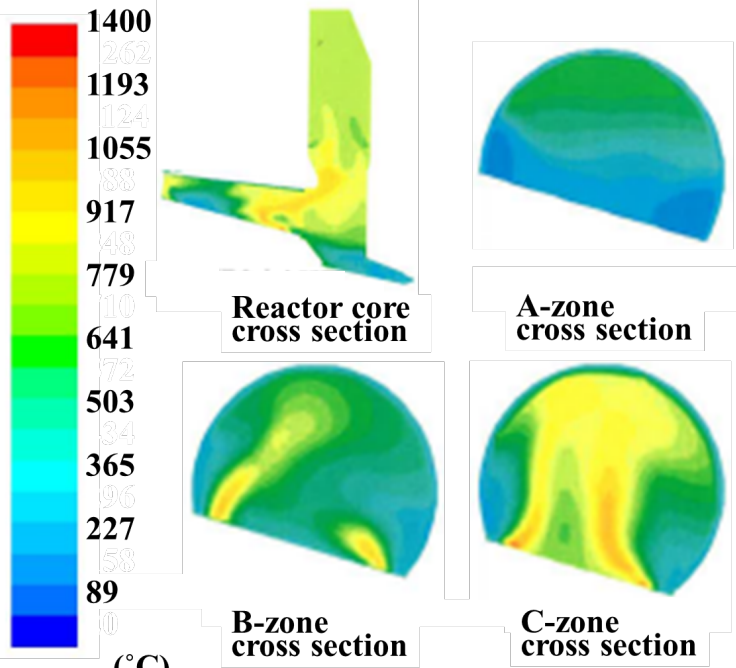

A-zone

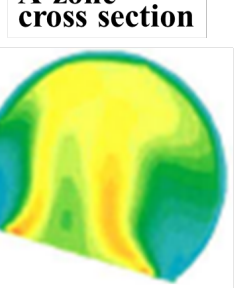

C-zone cross section

Figure 4. Combustion simulation with present waste composition (Case-2) when combustion air is supplied at $180^{\circ} \mathrm{C}$

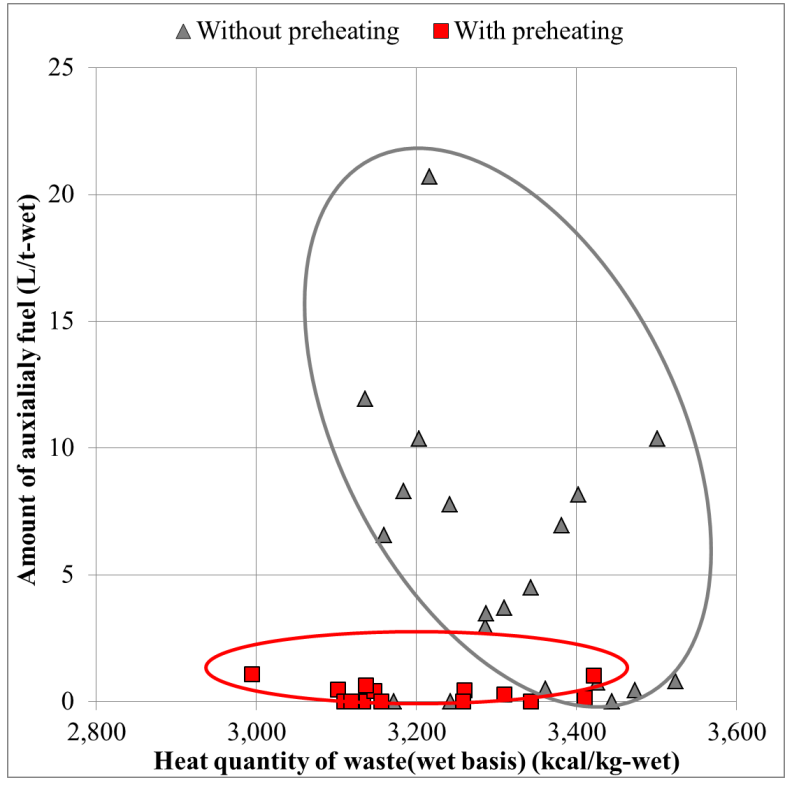

Figure 5. Relation between heat quantity of waste and amount of auxiliary fuel

preheated to $150-180^{\circ} \mathrm{C}$, and the triangle shows the case when it is not preheated (at room temperature).

It was found that the amount of auxiliary fuel could be suppressed by the preheated air even in the area where the heat quantity of waste was relatively low. 
Figure 6 shows the relation between heat quantity of waste and gas temperature in the top of the post combustion device

The square plot shows the case where combustion air is preheated to $150-180^{\circ} \mathrm{C}$, and the triangle plot shows the case where it is not preheated. A gas temperature of $300^{\circ} \mathrm{C}$ or less in the upper part of the post combustion device is taken as a control standard. It was confirmed when combustion air is preheated at $150-180^{\circ} \mathrm{C}$, the gas temperature in the top of the post combustion device is kept in the lower region, and is $300^{\circ} \mathrm{C}$ or less.

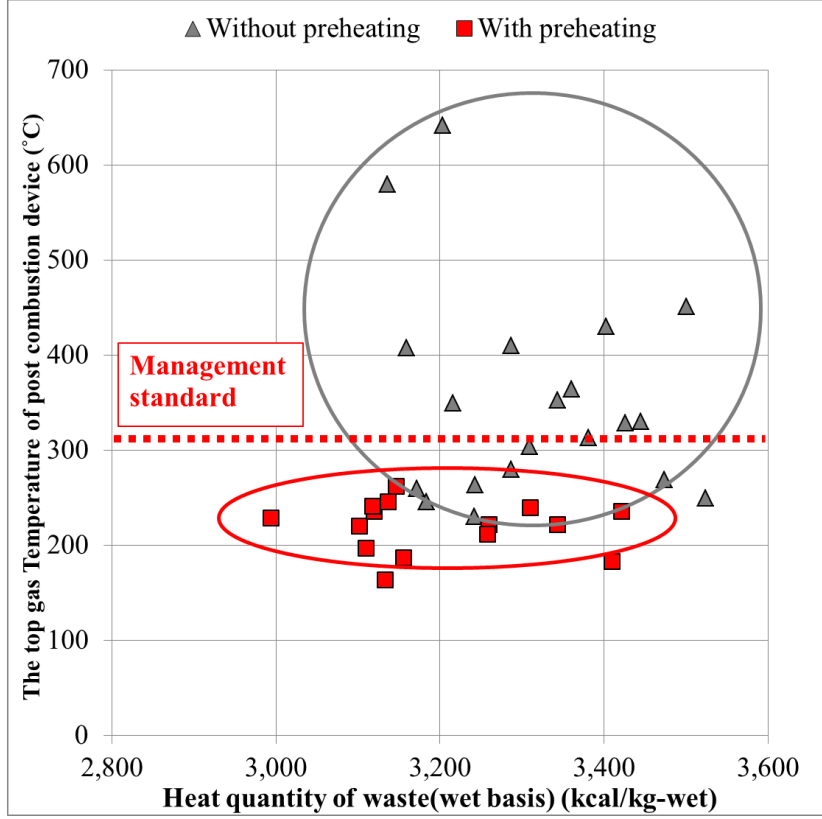

Figure 6. Relation between heat quantity of waste and gas temperature in the top of post combustion device

\section{Discussion}

As shown in Figure 3, the results of the combustion simulation when primary air is not preheated shows the temperature of the B-zone as well as the A-zone other than the ceiling part is mostly less than $500^{\circ} \mathrm{C}$. In the $\mathrm{C}$-zone, slight rise of the temperature can be observed which indicates the generation and burning of combustion gas. However, the temperature is still less than $500^{\circ} \mathrm{C}$ for the most part. On the other hand, as shown in Figure 4, the results of the combustion simulation when the primary air is preheated shows that the temperature of A-zone is generally lower compared to that of Figure 3 although the air heated up to $180^{\circ} \mathrm{C}$ is supplied. In the B-zone, however, noticeable rise of the temperature can be observed which is a clear evidence of the generation and burning of combustion gas, not observed in Figure 3. Moreover, in the $\mathrm{C}$-zone, the rise of the temperature becomes large and the temperature reaches up to $900^{\circ} \mathrm{C}-1000^{\circ} \mathrm{C}$. Also, the temperature of burning materials is supposed to increase from the B-zone toward the C-zone. In Figure 4, although the combustion air is preheated, the temperature of the Azone is lower than that when the primary air is not preheated. This can be explained by heat exchange between wastes and preheated air which evaporates moisture, leading to drying of wastes. Since primary air is supplied to the RC furnace as it is passed through waste, the preheated primary air contributes to drying of the wastes. In the combustion simulation, when the combustion air is preheated, the ambient temperature in the $\mathrm{RC}$ furnace reaches $900^{\circ} \mathrm{C}$ in the $\mathrm{B}$-zone, showing that full-scale combustion of waste is occurring in the B-zone. In a combustion air preheating experiment using an actual furnace, the effect of combustion air preheating appears as a change in the usage amount of auxiliary fuel. This suggests that excess water vaporizes in the A-zone, and waste was burned without any auxiliary fuel in the B-zone. Further, from the results of Figure 6, when combustion air is preheated as compared to the case when it is supplied at room temperature, the gas temperature in the top of the post combustion device decreases. It is considered that because combustion of wastes in the RC furnace has proceeded, there was less combustible residues at the RC furnace outlet, decreasing the combustion in the post combustion device. Thus, due to air preheating, drying proceeds efficiently and combustion of wastes in the RC furnace goes to completion, hence the operation of not only the RC furnace, but also the entire incineration facility including the post combustion device and secondary combustion chamber, is thought to be stabilized.

\section{Conclusion}

Preheating of primary air makes water in the waste vaporized rapidly, stabilizes combustion and decreases fuel consumption of wastes. It is confirmed that preheating of primary air has the effect of improving combustion.

\section{Acknowledgment}

We would like to express our sincere thanks to Kobelco EcoSolutions Co., Ltd. (formerly IHI Kankyo Engineering Co., Ltd.) for performing the combustion simulation in this study.

\section{References}

Denta, T., T. Nakayama, and T. Iwasaki; "Numerical Simulation of Combustion Behavior in Stoker-type Incineration System," JFE giho, 32, 61-66 (2013)

Inoue, S.; "Development of Waste Combustion and Melting System," PhD Thesis, Waseda University, Japan (2008)

Ministry of the Environment; FY 2018 White Paper on the Environment and White Paper Biodiversity, pp. 159-173, Ministry of the Environment ed., Tokyo, Japan (2018)

Narisawa, M.; "Newly Added Environmental Technologies and Products," Kobelco Eco-Solutions engineering reports, 15, 2-8 (2019)

Taniguchi, M., T. Fujiwara, and N. Takeda; "A Fundamental Study on Solid Waste Combustion," Environmental Engineering Research, 36, 391-401 (1999)

Yamaguchi, A., L. Dawei, and N. Haruo; "Development of Incinerator by Using Simulation Technology," EICA, 9, 30-36 (2004) 